\title{
Perceived Consumer Value of Omni-Channel Service Attributes in Japan and Korea
}

\author{
Renee B. Kim ${ }^{1}$, Takeshi Matsui ${ }^{2}$,Joonyong Park ${ }^{3}$, Takashi Okutani ${ }^{4}$ \\ ${ }^{1}$ Hanyang University \\ 605, School of Business, 222 Wangsimni-ro, Seongdong-gu, Seoul, Korea \\ E-mail.kimrby@gmail.com \\ ${ }^{2,4}$ Hitotsubashi University \\ School of Business \& Administration, 2-1, Naka, Kunitachi-shi. 186-8601, Tokyo Japan \\ E-mail.t.matsui@r.hit-u.ac.jp; takokutani2013@gmail.com \\ ${ }^{3}$ Hanyang University \\ 811, School of Business, 222 Wangsimni-ro, Seongdong-gu, Seoul, Korea \\ E-mail.hyjyphd@gmail.com \\ cross'ref $\underline{\text { http://dx.doi.org/10.5755/j01.ee.30.5.22820 }}$
}

Digitization of retail platform and integration of various retail channel is coupled with rapid change in consumer shopping behavior and their expectation for retail experience. Consumers expect retailers to be able to provide seamless, consistent and personalized service in which they also have enriched retail experience (Picot Coupey et al., 2016). Omni-channel retailing has emerged to provide integrated retail service of various channels which enable consumers to use various channels and touch points synergistically. In this study, we investigated the effect of perceived value of attributes of the OC service on consumers' decision process for omni-channel usage in Japan and Korea. The AHP method is applied to assess hierarchical process of consumers' decision making in using omni-channel service. In the AHP framework, consumers' decision making is structured hierarchically, and framed to have three levels of process in which consumers make decision on omni-channel usage based on three constructs: 'Customer Value (CV), 'Touch Point (TP)' and 'Payment System (PS)'. The AHP survey was administered to individual shoppers in Japan and Korea, and 240 respondents and 229 respondents answered the AHP survey in Korea and Japan, respectively. Findings reveal that 'Customer Value (CV)' is perceived to be more important than 'Touch Points (TP)' and the 'Payment System (PS)', affecting consumers' decision for using the omnichannel service. Furthermore, consumers in two countries show different preferences for specific aspects of the CV attributes. The authors also discuss the methodological and managerial implications of the findings.

Keywords: Omni-Channel Service; Customer Value; Touch Points; Payment System; Japan and Korea.

\section{Introduction}

Digitization of the marketplace brings evolution in consumers' behavior and expectation towards the retail service. Ubiquitous access to the Internet allows consumers to be able to consistently, interchangeably and simultaneously use a growing number of offline, online and mobile channels and touchpoints when shopping (Verheof et al., 2015). Consumers nowadays use various channels and touchpoints synergistically and expect retailers to be able to provide seamless, consistent and personalized service in which they also have enriched brand experience (Picot Coupey et al., 2016). Rapid change in consumer expectation and their behavior is coupled with greater complexity of the retail management which is driven by the digitalized retail format and integration of various channels. In particular, 'Omnichannel' (OC) retailing has emerged as an integrated sales experience that melds advantages of the physical stores with the information-rich experience of online shopping (Rigby, 2011; Kondo, 2018). The difference between physical online and online disappears, and the world turns into a showroom without walls (Brynjolfsson et al., 2013).
Retail channel integration lead the boundaries between the various channels and touchpoints to become blurred, thus the range of channel options and channel design to have greater complexity, posing a considerable challenge in retail management. This transformative process brings a 'fundamental change of the retailing paradigm' (Verhoef et $a l ., 2015$ ) and heightened pressure to retailers at a different level for rearranging their strategic channel management. The increase variety of channel formats and advances in single, multi-channel and omni-channel marketing have made shoppers more convenient to shop and buy, but marketers have become harder to manage (Ailawadi \& Farris, 2017). This development is affecting competitive strategies, as new channels will break down old barriers such as geography and consumer ignorance (Brynjolfsson et al., 2013). Concurrently, consumers' expectations of integrated uses of offline, online, and mobile touch points offer chances for retailers to create value and innovative offering designed to enhance consumer value and maximize firm value (Hure et al., 2017). Thus, competitive strategies of retailers need to be reconsidered to counter these developments. 
The retail industry must provide synergy management for numerous available channels and customer touchpoints in a way that optimizes customer experience and channel performance across multiple channels (Verhoef et al., 2015). Effective synchronization between online and offline channels is essential in enabling omni-channel journeys, consumers could gain high value and drive satisfaction, loyalty, and word-of-mouth marketing (Kumar and Reinartz, 2016; Leroi-Werelds et al., 2014; Hure et al., 2017). However, developing omni-channel initiatives is complex and difficult to manage for retailers (Hure et al., 2017). In order to respond to rapidly changing consumer expectation and behavior for evolving retail service, it is necessary to understand factors affecting consumer choice behavior for newly emerging retail service, and to determine whether consumers differentiate various aspects of the omni-channel attributes. Channel consolidation has been recognized as a promising strategy for retailers, but its impact on customer response to retailers and other channels is unclear. (Herhausen et al., 2015). The purpose of this paper is to assess consumers' perception towards omni-channel service attributes which are offered by retailers. Distinctive attributes of omni-channel service are selected in this study to evaluate whether they have meaningful effect on consumers' omni-channel choice. Findings provide insights to relative importance of perceived value of omni-channel service attributes, which provide guidelines for effective development of omni-channel infrastructure by retailers.

From a managerial point of view, knowledge of individual consumers' perceived value of attributes of OC service is crucial for the implementation of OC platform. Consumers' channel choice is likely to be affected by specific attributes of OC service which are offered by retailers. We apply AHP method to conceptually approximate consumers' decision making process on retail channel choice and usage. The AHP method effectively reveals the extent to which consumers are willing to use OC which contains distinctive attributes. Our study's contribution is threefold. First, on the methodological front, we apply AHP framework to examine the relationship between consumers' willingness to use OC service and the perceived value of the $\mathrm{OC}$ attribute, and provide empirical evidence as to whether this relationship is significant. Second, on the managerial front, we provide empirical insights of the extent to which consumers are willing to use the OC service, subject to OC retail attributes. These insights are of important value to retailers and marketing managers who need to implement the OC infrastructure, design associated marketing programs for OC retail service.

\section{Background}

Regarding channel integration, there seems to be competing arguments whether it can create competitive advantage. OC supporters argue that channel integration could strengthen customer value propositions (Gallino \& Moreno, 2014) or prevent customer confusion and frustration (Gulati \& Garino, 2000). Thus, the channel integration may provide evident value from customer's perspective. However, the channel integration may entail some potential risks from retailers' perspective, increasing 'research shopping' defined as the propensity of consumers to search in one channel then purchase through another channel - by more than 25 percent as it reduces channel-specific lock in effects (Verhoef et al., 2007). Additionally, the channel integration may also result in cannibalization of channels (i.e. the advantages of one channel are offset by the disadvantages of another, Falk et al., 2007) or negative spillover effects from one channel to another (Van Birgelen et al., 2006). In order to develop effective channel integration which can be performance enhancing, it is crucial to have good understanding of consumers' perception of OC retail attributes, which may facilitate development of an OC strategy.

Retail firms in Japan and Korea are chosen for the focus of this study as these markets are reinventing their retail strategies to gain competitive advantages and investing substantial resources in responding to transformation in the market place. Retailers in these two markets participate in multiple initiatives to synchronize offline and online, combine physical and digital touch points simultaneously, and manage retail mixes in a consistent way to ensure that the brand's fundamentals are aligned with every touch point (Picot-Coupey et al., 2016; Verhoef et al., 2015; Hure et al., 2017). Consumers in Japan and Korea are considered to have sophisticated and leading the shopping culture in Asian region. Although both of these countries have the retail sectors which are progressing rapidly toward digital commerce, yet consumer shopping culture and characteristics may differ to certain extent, thus it is worthwhile to have comparative understanding of consumers' perception towards newly offered attributes of OC retail services. Comparison of perceived value of OC retail attributes by Japanese and Korean consumers will present how determinants of $\mathrm{OC}$ retail platform play different role in these two major Asian retail markets.

\section{Retail Sectors \& Omni-Channel Development in Japan \& Korea}

Development of Omni-Channel in Japan has been recently initiated, which is evolving rapidly. Concurrently, adoption of smartphones by Japanese consumer reaches to more than $70 \%$ in 2017 (MIAC, 2017), which facilitates the OC retail development. With sophisticated infrastructure of eCommerce and digitally versatile consumer market, Japan is prone to have an efficient digital market environment. Reliable logistical system, low Internet fraud rates and overall convenience along with the high penetration rate of smartphone has led the rapid development of online retailing in Japan (AAFC, 2016). For example, online retailing in Japan expanded significantly for the 2010-2015, reaching USD65.2 billion in 2015. However, contrary to the rapidly evolving digital infrastructure, mobile shopping by Japanese consumers only accounts for $8 \%$ of monthly private consumption, and internet shopping account for $28 \%$, which is approximately half of the scale of US consumers' online shopping (MIAC, 2017). This may be partially due to fundamental difference in the retail structure between the two countries.

There are various types of retail formats in Japan, including department stores, general merchandise stores, convenience stores (CVS), specialty stores, and internet stores (Kondo, 2018). On the other hand, the U.S. has two types of retail formats such as offline stores and the Internet stores, and 
the simplified retail formats in the U.S. facilitate rapid development of omni-channels in the U.S. (Kondo, 2016). As each retail format needs different resources and capabilities to facilitate the OC strategy, it may be more challenging for Japanese retailers to develop Omni-channels due to the complicated structure of the retail sector in Japan. Nevertheless, in response to changing market and consumers, major Japanese retailers start to implement resources to integrate their brickand mortar and online strategies, and provide omni-channel service. For example, Seven \& i Holdings' has started an omnichannel retailing site, in which shoppers can place orders for items which are sold by the group's multitude of chains, and select a delivery method which provide options for shipping and pick-up at nearby shop.

Recently, Japanese retail brands, such as UNIQLO and MUJI have also launched the omni-channel platforms. MUJI has launched Digital CRM applications called 'MUJI passport' in 2013, and implemented this platform to other major Asian markets, including Hong Kong, Taiwan, China and Korea by the end of 2017. MUJI passport enables synergies between offline and online channels, as it offers various retail service functions (i.e. making purchases, checking into stores, posting product comments or participating in other promotions). It also facilitates customer engagement with its loyalty program, in which customers receive mileage, provide feedback and receive promotional information (KPMG, 2018). With the introduction of omnichannel service, these Japanese retailers provide seamless brand and shopping experiences. With increasing adoption of smartphone and mobile shopping by consumers, implementation of omni-channel service is expected to increase in the Japanese retail sector.

The retail sector in Korea is also characterized with several retail formats, department stores, hypermarkets, super supermarkets (SSM), convenience stores (CVS), specialty stores, and Internet stores. Thus, the retail structure in Korea is similar to the one in Japan. Among various retail channels, the online channel is found to have the biggest share $(18 \%)$ of distribution channel, followed by hypermarket segment. Department stores and Mom\& pop stores each takes $10 \%$ of the market, and CVS takes $7 \%$ of the share in 2016 (Statista, 2018). High population density (second in the world among more than 20 million people) and a high percentage of urban population (83\% in 2015) provide the perfect environment for the online retail industry to develop (Oh, 2017). The online retailer's total revenue amounted to 65.6 trillion won in 2016, and the food sector accounted for $13.4 \%$ of the online segment's revenue. Korea has one of the highest smartphone penetration in the world, with 36.3 million users, (i.e. more than two thirds of Korean consumers own one) (Statista, 2018). This provides an ideal environment for digitizing retail platform.

The online-shopping via mobile gears (smartphone and smart pads) is increasingly replacing desktop personal computer (PC) for online shopping, which provide more flexible shopping opportunity for consumers with no time and location barriers, thus mobile/on-line shopping is expected to continue its growth in Korea. With the rapid growth of Mobile shoppers in Korea, major retailers in Korea have initiated the implementation of omni-channel service to their platforms. Lotte, one of the largest Korean retailers, unfolds investment plan for approximately USD
2.8 billion to fortify its e-commerce business with omnichannel service in 2018. Lotte implemented IBM Watson solution to provide customer services based in AI, and introduced AI shopping guide Rosa. Rosa provides shopping solutions to online-customers through chatting based on the information collected from customer's purchase records, preference and personal records. Lotte is currently integrating mult-channels (i.e. TV home shopping, mobile and PC) into one platform which provide better access to customers (Yoo, 2018). Shinsegae, the leading retailer in Korea, is also investing approximately USD1billion to strengthen its e-commerce platforms (Kim, 2018). Furthermore, Shinsegae took initiatives in applying AI to enhance customer service experience, and has launched online search engine in May 2018, which applies deep learning, allowing consumers to search products based on images, instead of text. For offline service, Shinsegae provides customer service with AI 'ChatBot', providing automatic response by AI robot up to 24 percent of customer inquiry (Yoo, 2018). Thus, the Korean retail market is evolving progressively with rapid adoption of digital technology while Korean consumers are converting into digital shopping platform.

\section{Methodology}

\section{Analytic Hierarchy Process (AHP)}

Analytic Hierarchy Process (AHP) was developed to solve the multi-criteria decision problem (Saaty, 1977; Saaty, 1978; Saaty, 1979). Multi-criteria decision situation can be understood to comprise a hierarchy of decision criteria or objectives, and a decision goal (Lee et al., 2012). Various decision-making issues are generally based on multiple criteria and / or sub-criteria, and of their importance in making a decision (Crouch \& Ritchie, 2005). Therefore, it is necessary to evaluate the relative importance or weight given to each criterion. At each level, decisions can be made by aggregating all criteria weights. The AHP has been proven to provide a robust method for achieving this process (Saaty, 1979). The AHP has been applied to various empirical academic studies mainly due to attractive mathematical properties of the method and methodological convenience as necessary input data are relatively easy to obtain and it uses a multi-level hierarchical structure of objectives, criteria, sub-criteria (Lee et al., 2012). This approach is applied to various human judgment processes of management such as, economics, marketing, tourism and hospitality (Crouch \& Ritchie, 2005; Chen, 2006; Lin \& Wu, 2010; Tang, 2014; Kumar et al., 2015; Kumar \& Reinartz, 2016; Kim et al., 2017).

AHP related data is derived using a pair of comparisons. These comparisons are used to obtain a measure of the relative performance of the alternatives in terms of the weights of the materiality criteria and each individual decision criteria. If the comparison is not completely consistent, it provides a mechanism to improve consistency. There are three stages (Saaty, 2008; Luthra et al., 2013; Mani et al., 2014).

First: establish structure (hierarchical in nature) with decision elements (Figure 1 shows hierarchical structure to evaluate factors of omni-channel use); The factors for each criterion and subfactor should be related to each other. Once 
each element and its child elements are organized in a hierarchical order, the overall hierarchy setup for the target is complete (Saaty, 2008).

Second: construct pair wise comparison matrices (PWCMs); Cross-pair comparisons are performed for each factor that is converted to a numerical scale for each level according to the established layered structure process (Saaty, 2008). Comparison of criteria must be executed for the subject of comparison and the total number of comparisons is $\mathrm{n}(\mathrm{n}-1) / 2$ (Saaty, 2008).

Third: calculate the consistency using Equation (1) and Equation (2).

$$
\begin{aligned}
& \mathrm{CI}=(\lambda \max -n) /(n-1) \ldots \ldots . . \text { Equation }(1) \\
& \mathrm{CR}=\mathrm{CI} / \mathrm{RI} \ldots \ldots . . \text { Equation }(2)
\end{aligned}
$$

Each criterion/measurement is quantified by finding the values of the maximal eigenvalues, the consistency index (CI), and the consistency ratio (CR). AHP's CR index is used to ensure consistency in respondents' decisions. The value of RI depends upon the size matrix.

\section{Conceptual Framework}

Consumers' decision making for choosing important attributes of omni-channel service is conceptualized in the framework of the AHP (Figure 1). Consumers' decision making is structured hierarchically, and framed to have three levels of process. The third level for decision making shows 'omni-channel use' which is the final outcome of the decision making stage, and the second level includes three selected attributes of omni-channel services which are considered to be important from consumer perspectives, including a) provide more customer-touch points (TP), b) variety of payment systems (PS) and c) superior customer value (CV; experience). The first stage of decision making includes items which are considered for each of the three omni-channel attributes (i.e. TP, PS and CV). In total, five items are considered for the decision making of TP, three items for the decision making of PS, and seven items for the CV decision making, respectively (Figure 1). Based on the ratings obtained from the survey, the matrix is formulated and subsequent calculations are performed to prioritize using the AHP methodology.

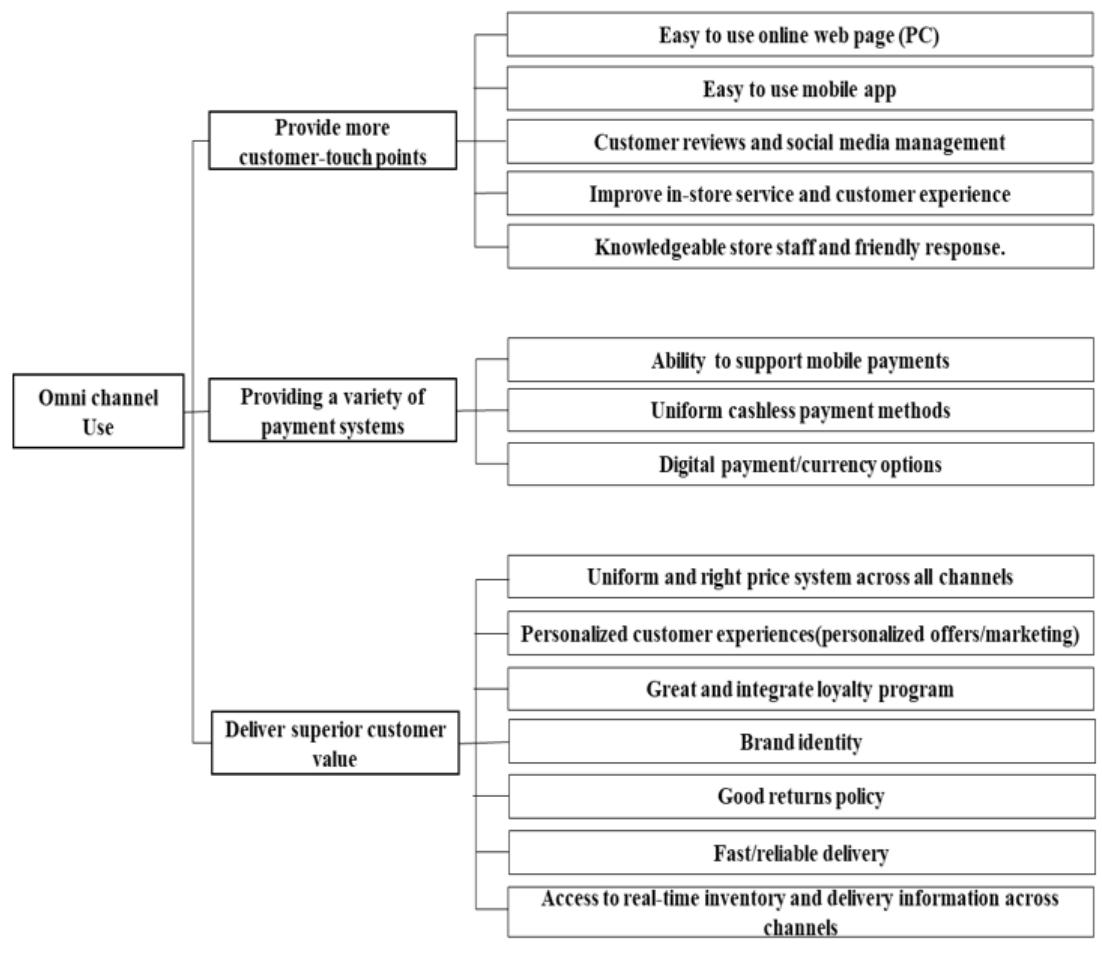

Figure 1. AHP Based Hierarchical Model to Evaluate Omni-Channel Use Factors

\section{Data Analysis and Results Samples}

We collected the survey data in Japan and Korea in the period of September to October 2018, which is based on AHP technique. The rating scale used in AHP is different from the simple Likert scale. In the AHP survey, ratings are pairwise compared against each other to derive their values. The rating scale is nonlinear-a more effective representation of what people really mean when they apply the ratings. This process is repeated to build different scales according to different criteria (David \& Saaty, 2007). The AHP survey was administered to individual shoppers in
Japan and Korea, 240 responses in Korea and 229 responses in Japan responses are collected. According Saaty (1980), If the $\mathrm{CR}$ value is too high, the decision about the selected preference is considered unreliable. In general, $\mathrm{CR}$ values in the range of 0.10 to 0.20 are suitable (Saaty, 1980; Millet \& Saaty, 2000). If the CR value exceeds 0.2 , then repetitively carry out the same procedure through feedback until the maximum Eigen value, CI, and CR value are satisfactory, or otherwise remove the outcome of such response (Lee et al., 2012). Thus, the responses with high $C R$ value are eliminated, and as a result, 167 responses (Korea) and 192 responses (Japan) responses were used in the analysis. Table 1 shows the respondents' demographic characteristics. 
Table 1

Demographic Characteristics

\begin{tabular}{|c|c|c|c|c|c|}
\hline \multirow{2}{*}{ Measure } & \multirow{2}{*}{ Items } & \multicolumn{2}{|c|}{ Korea } & \multicolumn{2}{|c|}{ Japan } \\
\hline & & Freq. & Percent & Freq. & Percent \\
\hline \multirow{2}{*}{ Gender } & Male & 91 & 54.5 & 121 & 63.0 \\
\hline & Female & 76 & 45.5 & 71 & 37.0 \\
\hline \multirow{5}{*}{ Age } & $\sim 10 \mathrm{~s}$ & 1 & .6 & 1 & .5 \\
\hline & $20 \mathrm{~s}$ & 101 & 60.5 & 191 & 99.5 \\
\hline & $30 \mathrm{~s}$ & 48 & 28.7 & & \\
\hline & $40 \mathrm{~s}$ & 16 & 9.6 & & \\
\hline & $50 \mathrm{~s} \sim$ & 1 & .6 & & \\
\hline \multirow{3}{*}{$\begin{array}{l}\text { Familiar with the } \\
\text { omni- channel } \\
\text { service }\end{array}$} & Well Know & 43 & 25.7 & 20 & 10.4 \\
\hline & $\begin{array}{l}\text { I was using, but I did not know it was called 'omni- } \\
\text { channel Service'. }\end{array}$ & 69 & 41.3 & 133 & 69.3 \\
\hline & I do not know much about omni- channel services. & 55 & 32.9 & 39 & 20.3 \\
\hline \multirow{6}{*}{$\begin{array}{l}\text { Satisfaction with } \\
\text { omni- channel } \\
\text { service }\end{array}$} & Very satisfied & 11 & 6.6 & 7 & 3.6 \\
\hline & Satisfaction & 70 & 41.9 & 73 & 38.0 \\
\hline & Normal & 86 & 51.5 & 50 & 26.0 \\
\hline & dissatisfaction & & & 3 & 1.6 \\
\hline & very dissatisfied & & & & \\
\hline & No experience & & & 59 & 30.7 \\
\hline \multicolumn{2}{|l|}{ Total } & 167 & 100 & 192 & 100 \\
\hline
\end{tabular}

Overall, respondent samples in Korea and Japan consist of slightly different gender proportion; Japanese sample had $63 \%$ male and $37 \%$ female, while Korean sample had $54.5 \%$ male and $45.5 \%$ female. Also, Korean sample some respondents in $30 \mathrm{~s}(28.7 \%)$ and in $20 \mathrm{~s}$ (60.5\%), while Japanese sample consist of primarily consumers in 20 s years old. In terms of knowledge and understanding of the OC service, higher percentage of Japanese respondents $(69.3 \%)$ were using the OC service without knowing, compared to the Korean respondents $(41.3 \%)$, and higher percentage of Korean respondents $(32.9 \%)$ did not know much about the OC service compared to the Japanese respondents $(20.3 \%)$. More interestingly, consumers in two countries showed different attitude towards the OC service. At large, Korean consumers appear to be more satisfied with the OC service (i.e. $41.9 \%$ satisfied; $51.5 \%$ normal), compared to Japanese consumers (i.e. $38 \%$ satisfied; $26 \%$ normal).

\section{AHP Results}

Table 2 shows pair wise comparison matrix (PWCM) indicating weights to dimensions, suggesting the rank among three selected attributes of OC service.

Table 2

PWCM of Criteria

\begin{tabular}{|c|c|c|c|}
\hline Criteria & Priority Matrix (Korea) & Rank & Priority Matrix(Japan) \\
\hline TP & 0.318111162 & $2^{\text {nd }}$ & 0.351103254 \\
\hline PS & 0.236051008 & $3^{\text {rd }}$ & 0.273698333 \\
\hline CV & 0.44583783 & $1^{\text {st }}$ & 0.375198413 \\
\hline C.I. & 0.098031848 & $3^{\text {rd }}$ \\
\hline C.R. & 0.169020427 & 0.079962278 \\
\hline
\end{tabular}

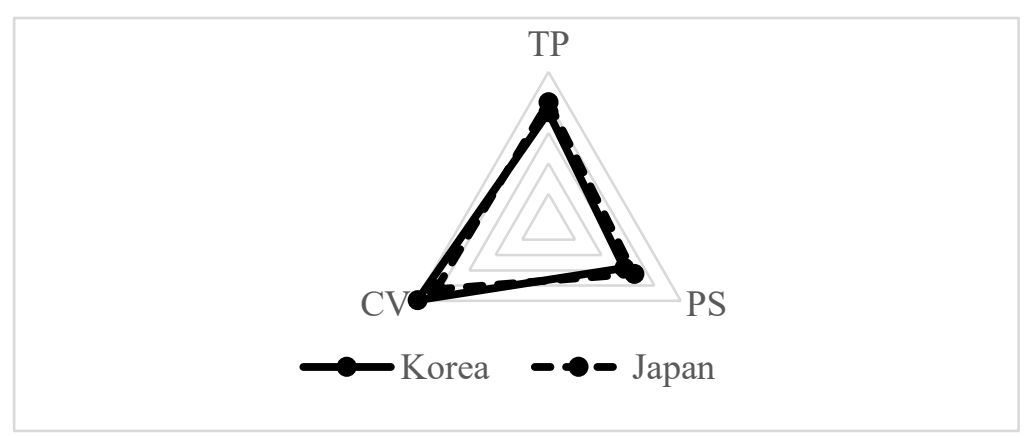

Figure 2. PWCM of Criteria

Table 2 and Figure 2 show that the Customer Value CV (K: 0.44583783; J: 0.375198413 ) was found to be the most important dimension for both Korea and Japan and TP was the second most important dimension for two countries regarding OC service (K: 0.318111162; J: 0.351103254). In the $3^{\text {rd }}$ level of decision making for OC service, Japanese and Korean consumers showed difference in their ranking for sub dimensions of OC attributes. 
PWCM of TP Dimension

\begin{tabular}{|l|c|c|c|c|}
\hline \multicolumn{1}{|c|}{ Criteria } & Priority Matrix (Korea) & Rank & Priority Matrix (Japan) & Rank \\
\hline Easy to use online web page (PC) & 0.155034263 & $5^{\text {th }}$ & 0.173880683 & $4^{\text {th }}$ \\
\hline Easy to use mobile app & 0.278954465 & $1^{\text {st }}$ & 0.236033841 & $1^{\text {st }}$ \\
\hline Customer reviews and social media management & 0.225311076 & $2^{\text {nd }}$ & 0.227433864 & $2^{\text {nd }}$ \\
\hline Improve in-store service and customer experience & 0.164434213 & $4^{\text {th }}$ & 0.205733928 & $3^{\text {rd }}$ \\
\hline Knowledgeable store staff and friendly response. & 0.176265983 & $3^{\text {rd }}$ & 0.156917685 & $5^{\text {th }}$ \\
\hline C.I. & 0.19439933 & \multicolumn{2}{|c|}{0.167305949} \\
\hline C.R. & 0.173570831 & \multicolumn{2}{|c|}{0.149380311} \\
\hline
\end{tabular}

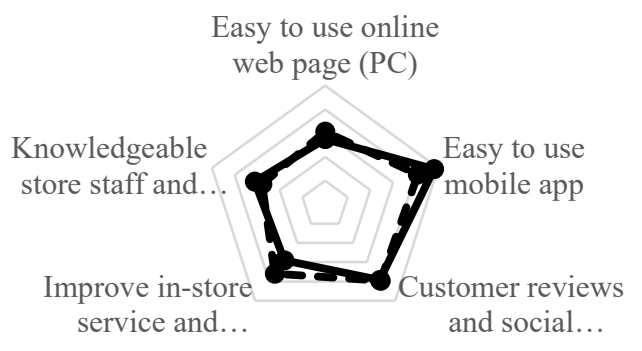

$\longrightarrow$ Korea $-\infty-$ Japan

Figure 3. PWCM of TP Dimension

Table 3 and Figure 3 report the relative importance of items considered for the attribute 'Touch Point'-TP. The first and the second rank of the TP items were found to be identical for Japanese and Korean consumers. For example, 'Easy to use mobile app' (K: 0.278954465; J: 0.236033841) was the most important item for the Touch-Point (TP) attribute, and 'customer review and social media management' was the second ranked item for the TP in two countries. However, the least important item of the TP was found to be different for Japanese and Korean consumers: Japanese chose 'Knowledgeable store staff and friendly response' to be least important, while Korean consumers chose 'Easy to use online web page (PC)' to be least important item.

Table 4 and Figure 4 show the ranking of items for the second OC attribute; Payment System (PS). Preferred items of the PS attributes were found to be identical for Japanese and Korean consumers. 'Digital payment/currency option' (K: 0.388558517 ; J: 0.527659866 ) was most important item of the PS attribute, and 'Ability to support mobile payments' was second most important item of the PS attribute (Table 4).

PWCM of PS Dimension

\begin{tabular}{|c|c|c|c|c|}
\hline Criteria & Priority Matrix (Korea) & Rank & Priority Matrix (Japan) & Rank \\
\hline Ability to support mobile payments & 0.357785778 & $2^{\text {nd }}$ & 0.27430078 & $2^{\text {nd }}$ \\
\hline Uniform cashless payment methods & 0.253655705 & $3^{\text {rd }}$ & 0.198039354 & $3^{\text {rd }}$ \\
\hline Digital payment/currency options & 0.388558517 & $1^{\mathrm{st}}$ & 0.527659866 & $1^{\text {st }}$ \\
\hline C.I. & \multicolumn{2}{|l|}{0.093628303} & \multicolumn{2}{|l|}{0.081114743} \\
\hline C.R. & \multicolumn{2}{|l|}{0.161428109} & \multicolumn{2}{|l|}{0.139853005} \\
\hline
\end{tabular}

Table 4

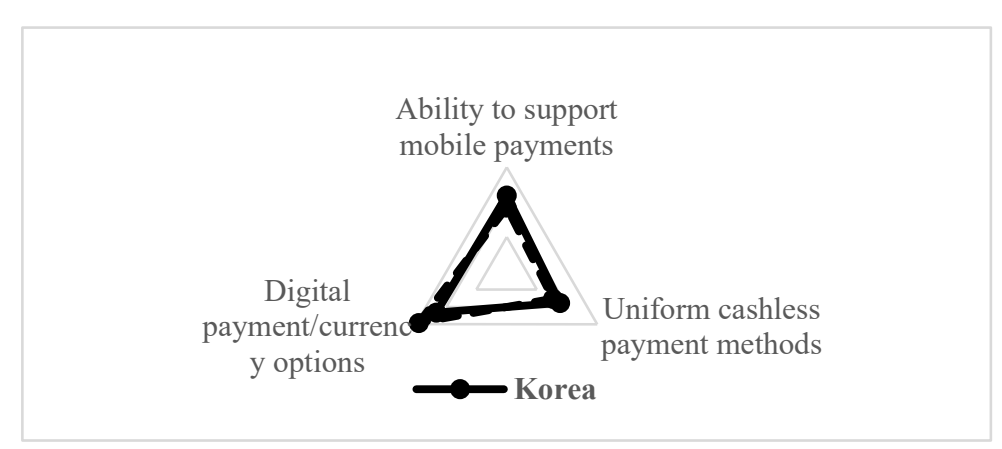

Figure 4. PWCM of PS Dimension 
Table 5 and Figure 5 present relative importance of items for the attribute, Customer Value (CV). 'Fast/reliable delivery' (K: 0.194773119; J: 0.209072677) was chosen by both Japanese and Korean consumers as the most important item of the $\mathrm{CV}$ attribute. Yet, the ranking of other items were found to be different between these two consumer groups.

Table 5

PWCM of CV Dimension

\begin{tabular}{|c|c|c|c|c|}
\hline Criteria & $\begin{array}{c}\text { Priority Matrix } \\
\text { (Korea) }\end{array}$ & Rank & $\begin{array}{c}\text { Priority Matrix } \\
\text { (Japan) }\end{array}$ & Rank \\
\hline Uniform and right price system across all channels & 0.128721471 & $5^{\text {th }}$ & 0.101228557 & $6^{\text {th }}$ \\
\hline Personalized customer experiences (personalized offers/marketing) & 0.132641051 & $4^{\text {th }}$ & 0.108505777 & $5^{\text {th }}$ \\
\hline Great and integrate loyalty program & 0.109173368 & $7^{\text {th }}$ & 0.094770228 & $7^{\text {th }}$ \\
\hline Access to real-time inventory and delivery information across channels & 0.184387159 & $2^{\text {nd }}$ & 0.144820992 & $4^{\text {th }}$ \\
\hline Brand identity & 0.113491778 & $6^{\text {th }}$ & 0.151597759 & $3^{\text {rd }}$ \\
\hline Fast/reliable delivery & 0.194773119 & $1^{\mathrm{st}}$ & 0.209072677 & $1^{\text {st }}$ \\
\hline Good returns policy & 0.136812054 & $3^{\text {rd }}$ & 0.190004011 & $2^{\text {nd }}$ \\
\hline C.I. & \multicolumn{2}{|c|}{0.245244384} & \multicolumn{2}{|c|}{0.230953849} \\
\hline 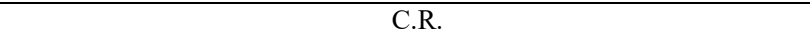 & \multicolumn{2}{|c|}{0.17517456} & \multicolumn{2}{|c|}{0.164967035} \\
\hline
\end{tabular}

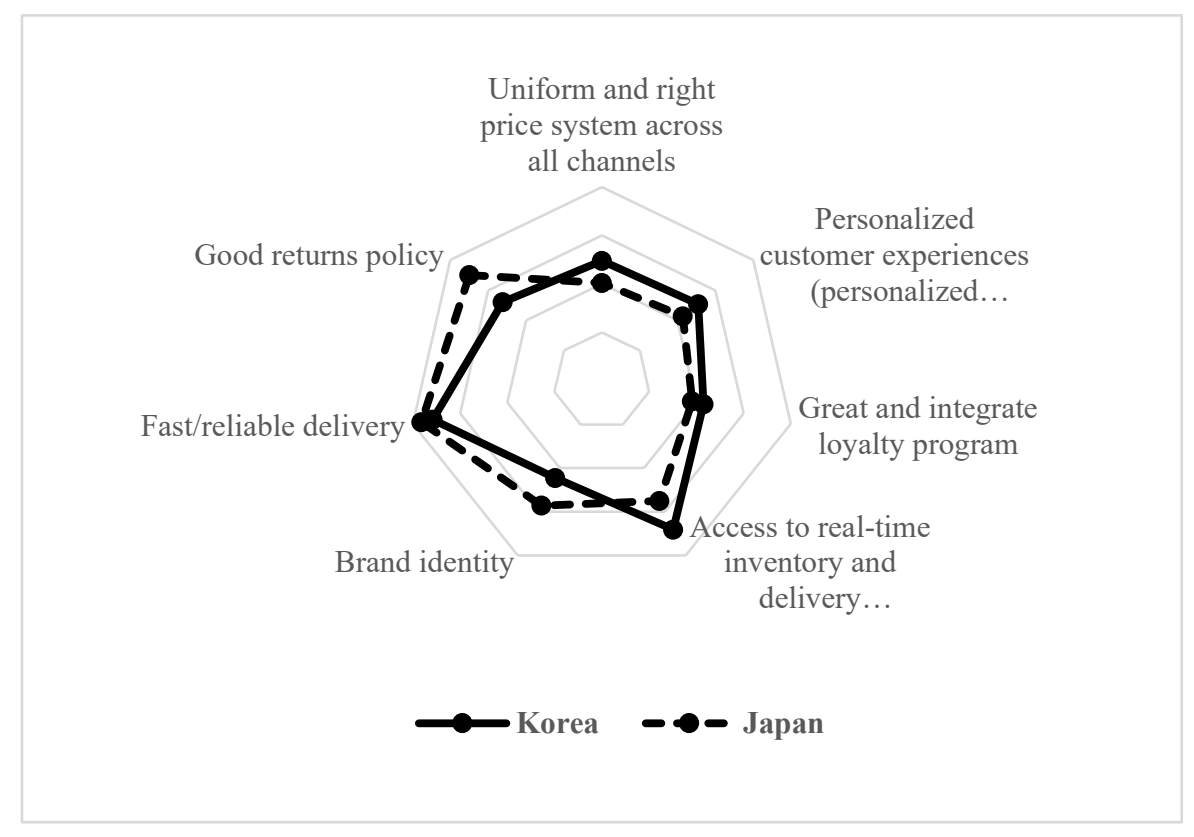

Figure 5. PWCM of CV Dimension

\section{Discussion}

In this study, we investigated how perceived value of attributes of the OC service affects consumers' decision process for OC usage in Japan and Korea. These countries are at developmental stage of the $\mathrm{OC}$ infrastructure in the retail sector, and have the highest rate of smartphone penetration in Asia. The AHP method allows us to assess hierarchical process of consumers' decision making in using the OC service. In our model, consumers' decision making involves three stages for using the OC service.

The second stage of consumers' decision making involves pair-wise comparison of three selected attributes (i.e. CV, PS and TP) of the OC services (Table 2). The pair wise comparison matrix (PWCM) of these three selected attributes show that Japanese and Korean consumers consider 'Customer Value' (CV) to be the most important attribute of OC service, affecting their intention to use OC service. Two consumer groups showed identical preference for the other two attributes; choosing 'Touch Point' (TP) and
'Payment System' (PS) as second and third most important attributes regarding OC service usage. Thus, both Japanese and Korean consumers appear to have similar view on important aspects of the OC service at macro-level. However, regarding assessment of sub-dimension of $\mathrm{OC}$ service attribute, consumers in two countries showed considerably different preference.

In particular, the PWCM of the CV attribute exhibits most interesting disparity between Japanese and Korean consumers' preferences for the OC service (Table 5). While 'fast/reliable delivery' was selected as the most important aspect of the $\mathrm{CV}$ for OC service by consumers in both countries, different factors were chosen for the rest of the $\mathrm{CV}$ rankings by the two groups.

Japanese consumers consider 'Good return policy' as the second most important factor of the $\mathrm{CV}$ attribute, and 'Brand identity' as the third most important factor of the CV attribute (Table 5). On the other hand, Korean consumers selected 'Access to real-time inventory \& delivery information access across channels' as the second, and 
'Good return policy' as the third important factors of the CV attribute. In particular, Korean consumers perceived 'Brand identity' as relatively less important factor of the CV attribute (i.e. ranked as sixth important factor), showing contrasting preference compared to Japanese. Japanese consumers pay attention to brand name, trust of the retailers in using the $\mathrm{OC}$ service since the OC services are primarily offered by major retailers who have high brand recognition domestically and internationally. Thus, retailers' brand reputation may help consumers' consideration for using the OC service in Japan.

On the other hand, 'Brand identity' was found to be one of the least important factors of the CV attribute in Korea. Korean consumers appear to focus more on functional aspects of the OC service, such as 'fast/reliable delivery' and 'availability of real-time inventory \& delivery information across channels'. Korean consumers have different shopping culture and consumer characteristics. Rapidness is considered to be highly important not only in Korean shopping culture but also in overall service sector in Korea. On the other hand, rapidness of service is not as highly valued by Japanese consumers. The difference in shopping culture and consumer preference for service was evidently reflected in the different preference for the CV attribute of the OC service. 'Integrated Loyalty program' was found to be the least important factor of the CV attribute in Korea.

Regarding the 'Touch Point' (TP) attribute, Japanese and Korean consumers showed mixed preferences (Table 3). 'Easy to use mobile app' was found to be the most important factor of the TP attribute, and 'Customer review \& social media management' was the second most important factor of the TP for both consumer groups (Table 3). This finding clearly show the rising popularity of mobile shopping in these two markets and consumers revealed strong interest in mobile app. Social media has become a mainstream medium of marketing communication, influencing consumers' shopping behavior in both countries, and their interest in this factor support the current market conditions.

'Easy to use online web page (PC)' was ranked as $5^{\text {th }}$ by Korean and $4^{\text {th }}$ by Japanese consumers, and offline service attributes such as 'Improve in-store service \& customer experience' and 'Knowledgeable store staff and friendly response' are found to be relatively insignificant aspect of the OC service (Table 3). This implies that consumers are evidently moving away from offline to online for shopping experience. Also, as consumers have more access to information through various channels, they tend to less dependent on offline store staffs for information and service.

For the 'Payment System (PS)' attribute, consumers in both countries showed identical preference regarding the rank of important factors of the PS (Table 4). Two consumers group chose 'Digital/currency options' as the most important factor, and 'Ability to support mobile payments' as the second most important factor. 'Uniform cashless payment methods' was chosen as the least important factor of the TP construct.

\section{Managerial Implications}

This study draws managerial attention in various aspects. First, we found that consumers in both countries consider 'Customer Value (CV)' to be more important than 'Touch Points (TP)' or 'Payment Method (PM)' as the OC service attributes. Of the several items listed in the $\mathrm{CV}$ attributes, 'Fast/reliable delivery' was found to be most critical service attribute for both consumer groups. From a firm's perspective, it is therefore worthwhile to allocate substantial resource to establish an efficient delivery system as part of competitive strategy. Second, there was disparity of consumer preference for other factors of the $\mathrm{CV}$ attributes between Japanese and Korean consumer markets. Thus, retailers in these countries need to respond to the pressure for local responsiveness. As OC efforts by retailers have increased, they need to combine, manage and reward different types of channels to match how consumers want to search, buy and return (Ailawadi \& Farris, 2017). Our finding show that consumers in different show different shopping culture and consumer characteristics, thus retailers' ability to design OC retail platform to address specific granularity of consumer preference become more imperative for competitive advantage.

Japanese retailers should continue to enhance brand reputation and trust with continuous branding investments in addition to building an efficient infrastructure for digital commerce. Brand equity means evaluating the subjective and intangible of the brand, above and beyond objectively perceived value (Rust et al., 2000), which leads to customer satisfaction. Customer satisfaction affects the success of the company as a psychological and emotional result of personal experience (Baker \& Crompton, 2000; Nam et al., 2011; Lin, 2015). Thus, branding investment may need to involve branding efforts not only around service features, but also subjective aspects of brand experience by consumers.

Consumers perceive that they live an experience with a brand rather than with a channel, and branding becomes more important in an OC context because the brand is at the crossroads of the touch points (Hure et al., 2017). Thus, retailers may need to lock-in consumers within the brand ecosystem, and this reinforces consumer loyalty (Verhoef et al., 2015; Hure et al., 2017). The true loyalty of consumers to retail is reflected in their willingness to search for their favorite products, whether to change stores to find their favorite brands (Ailawadi \& Farris, 2017). If a retailer's brand strength is recognized by consumers and translated into true brand loyalty, consumers will likely to be willing to switch brands to shop at their favorite store (Ailawadi \& Farris, 2017). Since Japanese consumers considered brand identity of retailer to be an important part of their value, it is worthwhile for retailers to invest in building brand loyalty.

In contrast to Japanese case, Korean consumers place more value to functional aspects of the omni-channel service in defining the Customer Value (CV). 'Good return policy' and 'Access to real-time inventory \& delivery information across channels' were found to be significant factors in the Korean case. Major Korean retailers are learning to ride the 'big data' trend and implementing various types of marketing metrics to track more channels and to manage them effectively. These efforts may enable them to provide more efficient approach to aid consumers' search behavior and after purchase service.

Third, findings show the rising importance of the use of mobile. Both Japanese and Korean consumers selected 'Easy to use mobile app' as the most critical factor of the 'Touch Points (TP) attribute. Two consumer groups also identified 'Ability to support mobile payment' as the most 
important factor of the 'Payment System (PS)'attribute. These findings support consumers are rapidly adopting the mobile app to aid their shopping. As consumers look for more convenience and ease of transaction online, how the mobile app is designed and connected with an efficient delivery and payment system are likely to become critical factor, determining the successful implementation of OC service by retail firms. Marketers should help consumers find and access offline stores as well as online and mobile has expanded both capabilities, as it complements both channels and aid consumer to a website or a product page online based on a description, a scanned barcode, or a photo (Ailawadi \& Farris, 2017).
Lastly, our study suggests that consumers consider using OC for different aspects of convenience (searching, ordering and delivery) and 'seamlessness' or 'perceived consistency' among the retail mix of touch points is found to be a primary reason to use the OC retail service (Park \& Kim, 2018). Thus, returns on a company's effort to establish a successful OC (i.e. from consumers' perspective) depend on whether consumers can have shopping experience seamlessly, moving smoothly from one touch point to another (Brynjolfsson et al., 2013; Fulgoni, 2014). In other words, all three attributes identified in the OC service (e.g. CV, TP, and PS) should be synergistically linked and managed to provide a frictionless shopping experience for consumers. (Picot-Coupey et al., 2016; Brynjolfsson et al., 2013).

\section{Acknowledgement}

This work was supported by the Ministry of Education of the Republic of Korea and the National Research Foundation of Korea (NRF-2016S1A3A2924243)

\section{References}

AAFC (June 10, 2018). Modern Grocery Retailing in Japan, March 2016, Market Access Secretariat: global Analysis Report. Retrieved from http://www.agr.gc.ca/resources/prod/Internet-Internet/MISB-DGSIM/ATS-SEA/PDF/6731-eng.pdf.

Ailawadi, K. L., \& Farris, P. W. (2017). Managing multi- and omni-channel distribution: Metrics and Research Directions. Journal of Retailing, 93(1), 120-135. https://doi.org/10.1016/j.jretai.2016.12.003

Baker, D. A., \& Crompton, J.L. (2000). Quality, satisfaction and behavioral intentions. Annals of Tourism Research, 27(3), 785-804. https://doi.org/10.1016/S0160-7383(99)00108-5

Brynjolfsson, E. Hu, Y. J., \& Rahman, M. S. (2013). Competing in the age of omnichannel retailing. MIT Sloan Management Review, 54(4), 23-29.

David, J., \& Saaty, D. (2007). Use analytic hierarchy process for project selection. In ASQ Six sigma forum magazine, 6(4), 22-29.

Falk, Thomas, Schepers, J., Hammerschmidt, M., \& Bauer, H. H. (2007). Identifying cross-channel dis-synergies for multichannel service providers. Journal of Service Research, 10(2), 143-60. https://doi.org/10.1177/109467 0507306683

Fulgoni, G. M. (2014). "Omni-channel" retail insights and the consumer's path-to-purchase: how digital has transformed the way people make purchasing decisions. Journal of Advertising Research, 54(4), 3877-380. https://doi.org/10.2501/JAR54-4-377-380

Gallino, S., \& Moreno, A. (2014). Integration of online and offline channels in retail: the impact of sharing reliable inventory availability information. Management Science, 60(6), 1434-51. https://doi.org/10.1287/mnsc.2014.1951

Gulati, R. \& Garino, J. (2000). Get the right mix of bricks \& clicks. Harvard Business Review, 78(3), $107-14$.

Herhausen, D., Binder, J., Schoegel, M., \& Herrmann, A. (2015). Integrating bricks with clicks: retailer-level and channellevel outcomes of online-offline channel integration. Journal of retailing, 91(2), 309-325. https://doi.org/10.1016/ j.jretai.2014.12.009

Hure, E., Picot-Coupey, K., \& Ackermann, C. L. (2017). Understanding omni-channel shopping value: A mixed-method study. Journal of Retailing and Consumer Services, 39, 314--330. https://doi.org/10.1016/j.jretconser.2017.08.011

Park, J., \& Kim, R. B. (2018). A new approach to segmenting multichannel shoppers in Korea and the US. Journal of Retailing and Consumer Services, 45, 163-178. https://doi.org/10.1016/j.jretconser.2018.09.007

Kim, N., Park, J., \& Choi, J. J. (2017). Perceptual differences in core competencies between tourism industry practitioners and students using Analytic Hierarchy Process (AHP). Journal of Hospitality, Leisure, Sport \& Tourism Education, 20, 76-86. https://doi.org/10.1016/j.jhlste.2017.04.003

Kim, D. S. (June 9, 2018). Lotte shopping to invest W3tr for e-commerce under omni-channel. Korea Herald. Retrieved from http://www.koreaherald.com/view.php?ud=20180515000703.

Kondo, K. (2016). Characteristics of the Japanese Type of Omni-channel Retailing. 2016 Global Marketing Conference at Hong Kong Proceedings: 856-860 (July 2016). Retrieved from http://gmcproceedings.net/html/sub3_01.html.

Kondo, K. (2018). Retail corporate groups: Challenges of omnichannel management in Japan. Journal of Marketing Channels, 25(4), 245-248. https://doi.org/10.1080/1046669X.2019.1658016

KPMG (June 10, 2018). The truth about online consumers: 2017 Global Online Consumer Report. Retrieved from https://assets.kpmg.com/content/dam/kpmg/xx/pdf/2017/01/the-truth-about-online-consumers.pdf. 
Kumar, S., Luthra, S., Haleem, A., Mangla, S. K., \& Garg, D. (2015). Identification and evaluation of critical factors to technology transfer using AHP approach. International Strategic Management Review, 3(1), 24-42. https://doi.org/10. 1016/j.ism.2015.09.001

Kumar, V., \& Reinartz, W. (2016). Creating enduring customer value. Journal of Marketing. 80(6), 36-68. https://doi.org/10.1509/jm.15.0414

Lee, S., Kim, W., Kim, Y. M., \& Oh, K. J. (2012). Using AHP to determine intangible priority factors for technology transfer adoption. Expert Systems with Applications, 39(7), 6388-6395. https://doi.org/10.1016/j.eswa.2011.12.030

Lin, Y. H. (2015). Innovative brand experience's influence on brand equity and brand satisfaction. Journal of Business Research, 68(11), 2254-2259. https://doi.org/10.1016/j.jbusres.2015.06.007

Luthra, S., Garg, D., \& Haleem, A. (2013). Identifying and ranking of strategies to implement green supply chain management in Indian manufacturing industry using analytical hierarchy process. Journal of Industrial Engineering and Management, 6(4), 930-62. https://doi.org/10.3926/jiem.693

Mani, V., Agarwal, R., \& Sharma. V. (2014). Supplier selection using social sustainability: AHP based approach in India. International Strategic Management Review, 2(2), 98-112. https://doi.org/10.1016/j.ism.2014.10.003

METI, J. (2017). Key Points of the 2017 White Paper on Information and Communications in Japan

Millet, I., \& Saaty, T. L. (2000). On the relativity of relative measures accommodating both rank preservation and rank reversals in the AHP. European Journal of Operational Research, 121(1), 205-212. https://doi.org/10.1016/S03772217(99)00040-5

MIAC (June 10, 2018). 2017 White Paper on Information and Communications in Japan: Data-driven economy and social change, Ministry of International Affairs and Communication, July 2017. Retrieved from http://www.soumu.go.jp/ main_content/000504683.pdf.

Nam, J., Ekinci, Y., \& Whyatt, G. (2011). Brand equity, brand loyalty and consumer satisfaction. Annals of Tourism Research, 38(3), 1009-1030. https://doi.org/10.1016/j.annals.2011.01.015

Oh, S. (2017). Korea-Republic of, Retail Foods: Biennial Report 2017. GAIN Report Number: KS1729. Retrieved from https://gain.fas.usda.gov/Recent\%20GAIN\%20Publications/Retail\%20Foods_Seoul\%20ATO_Korea\%20\%20Republic\%20of_2017-09-26.pdf.

Picot-Coupey, K., Hure, E., \& Piveteau, L. (2016). Channel design to enrich customers' shopping experiences: Synchronizing clicks with bricks in an omni-channel perspective-the Direct Optic case. International Journal of Retail \& Distribution Management, 44(3), 336-368. https://doi.org/10.1108/IJRDM-04-2015-0056

Rigby, D. (2011). The future of shopping. Harvard Business Review,89(12), 65-76.

Rust, R. T., Zeithaml, V. A., \& Lemon, K. N. (2000). Driving customer equity: How customer lifetime value is reshaping corporate strategy. New York: The Free Press.

Saaty, T. L. (1977). A scaling method for priorities in hierarchical structures. Journal of Mathematical Psychology, 15(3), 234-281. https://doi.org/10.1016/0022-2496(77)90033-5

Saaty, T. L. (1978). Modeling unstructured decision problems-the theory of analytical hierarchies. Mathematics and Computers in Simulation, 20(3), 147-158. https://doi.org/10.1016/0378-4754(78)90064-2

Saaty, T. L. (1979). Applications of analytical hierarchies. Mathematics and Computers in Simulation, 21(1), 1-20. https://doi.org/10.1016/0378-4754(79)90101-0

Saaty, T. L. (2008). Decision making with analytic hierarchy process. International Journal of Services Sciences, 1(1), 8398.https://doi.org/10.1504/IJSSCI.2008.017590

Statista (June, 2018) Number of smartphone users in top 15 countries worldwide, as of April 2017 (in millions). Retrieved from https://www.statista.com/statistics/748053/worldwide-top-countries-smartphone-users/

Statista (June 9, 2018). Share of distribution channel in South Korea's retail market in 2016, The Statistics Portal. Retrieved from https://www.statista.com/statistics/739806/south-korea-share-of-retail-market-distribution-channel/.

Van Birgelen, M., De Jong, A., \& De Ruyter, K. (2006). Multi-channel service retailing: The effects of channel performance satisfaction on behavioral intentions. Journal of Retailing, 82(4), 367-377. https://doi.org/10.1016/j. jretai. 2006.08.010

Verhoef, P. C., Neslin, S. A., \& Vroomen, B. (2007). Multi-channel customer management: understanding the research shopper phenomenon, International Journal of Research in Marketing, 24(2), 129-44. https://doi.org/10. 1016/j.ijresmar.2006.11.002

Verhoef, P. C., Kannan, P. K., \& Inman, J. J. (2015). From multi-channel retailing to omni-channel retailing: introduction to the special issue on multi-channel retailing. Journal of retailing, 91(2), 174-181. https://doi.org/10. 1016/j.jretai.2015.02.005

Yoo, S. J. (June 9, 2018). AI is a new trend in Korean retail sector. Is Retail 4.0 feasible ? MondayNews (MDN). June 9th 2018. Retrieved from http://www.wolyo.co.kr/news/articleView.html?idxno=60434.।

The article has been reviewed.

Received in February 2019; accepted in December 2019. 